\title{
Biodeterioration of Optical Glass Induced by Lubricants Used in Optical Instruments Technology
}

\author{
MAGDALENA BARTOSIK ${ }^{1}$, ZOFIA ŻAKOWSKA $^{1 *}$, KRYSTYNA CEDZIŃSKA $^{2}$ \\ and KAZIMIERZ ROŻNIAKOWSKI ${ }^{3}$ \\ ${ }^{1}$ Institute of Fermentation Technology and Microbiology, Technical University of Łódź, Poland \\ ${ }^{2}$ Institute of General Food Chemistry, Technical University of Łódź, Poland \\ ${ }^{3}$ Institute of Physics, Technical University of Łódź, Poland
}

Received 23 March 2010, revised 22 October 2010, accepted 25 October 2010

\begin{abstract}
The process of biodeterioration of optical glass was studied after being induced by an auxiliary material (lubricant 4CKP) used in the production of optical instruments. It was determined that the lubricant can initiate growth of conidia of Aspergillus niger fungus. Acid spawn metabolites cause deterioration of the glass surface. Measurements of laser light beam transmittance through the glass plate and the AAS chemical analysis method of the post-culture fluid allowed to determine that glass with a high $\mathrm{SiO}_{2}$ content is most resistant to corrosion caused by the growth of $A$. niger fungi spawn
\end{abstract}

K e y w ord s: atomic absorption spectrometry (AAS), biodeterioration, lubricant, optical glass, transmitation of laser beam

\section{Introduction}

The ubiquitous existence of microorganisms in all natural environments as well as their unusual capability to adapt to various conditions is the cause of biological deterioration and corrosion of most existing technical materials.

It would be difficult to mention a group of materials not affected by microorganisms either in a destructive way or at least with a change of their properties. Microorganisms change the properties of many materials used among others in construction, packing, fabrics, synthetic materials, lubricants, metals and alloys (Zyska, 2001; Cwalina, 2003; Janda, 2005; Szumigaj et al., 2008).

The process of biodeterioration also affects such a stable material as glass. It was determined already in 1943 in Japan that mould grows on optical glass and this was later confirmed in 1958 in the famous Commonwealth Mycological Institute in Kew, Great Britain (Ohtsuki, 1943; Dade, 1958).

Signs of glass microbiological corrosion were more precisely described by Kerner-Gang in 1968. Pits in the optical glass were caused by Aspergillus versicolor conidia already after 5 days. This destructive process is slower when Penicilium funiculosum, Alternaria tenuis and Aspergillus fischeri fungi are present.

Gorbuhina and Palinska (1999) studied the role of fungi and cyanide bacteria in the process of destroying glass produced similarly as medieval church windows. On the glass surface they found a film consisting of bacteria such as Synechococcus sp., Merismopedia glauca, Chroococcidiopsis sp. and fungi Aureobasidium sp., Acremonium sp., and Trimmatostroma sp. After removal of the biological material the glass surface also showed pits, slots and figures.

Reports also mention microbiological corrosion of window glass in the Cister church in Hanau (Germany). It is suspected that in the course of earlier restoration works they were covered with a substance rich in carbon. In summer the relative humidity inside the church reached $80 \%$ and the average temperature was $18^{\circ} \mathrm{C}$. Such conditions and source of carbon enhanced the growth of fungi on the glass surface (Weissaman and Drewello, 1996).

Growth of fungi was also observed on stained glass windows in a medieval monastery in Hanterive (France). Some 20 types of fungi including Taeniolina

* Corresponding author: Z. Żakowska, Institute of Fermentation Technology and Microbiology, Technical University of Łódź; Wólczańska 171/173, 90-924 Łódź, Poland; e-mail: zofia.zakowska@p.lodz.pl 
deightonii belonging to the Demiataceae family (Kaiser et al., 1996) were isolated from infected glass.

Analysis was also made of the deterioration of historical stained glass windows in the $15^{\text {th }}$ century Cartuja de Miraflores monastery in Spain. Biodeterioration of the window glass was found during renovation conducted in 2003. Pits and slots, often filled with white deposits, were observed on the glass surface. Aspergillus type are responsible for this phenomena. Together with bacteria they colonized the glass surface (Carmena et al., 2006).

Fungi are the dominant species in microflora on the glass surface and their metabolites are responsible for the irreplaceable changes and degradation of the structure and composition of this inorganic material (Watkins, 2003).

Fungi growth often deteriorate glass surface and cause its darkening and discoloration. On the other hand, deposits are formed on the surface due to the reaction between mould metabolites and glass components (Weismann and Drewello, 1996; Bartosik et al., 2007).

So far studies of microbiologically induced glass corrosion were mainly focused on the analysis of destructive changes occurring on stained glass and windows in old churches. In this area of research, studies of optical glass resistance to various environmental conditions and especially to microorganisms are much less common. Also in Poland such studies have not been undertaken by research centers.

Estimation of the resistance of optical instruments to microbiological corrosion is important and justified since they are used both in civil and military applications and they can be deteriorated both by environmental and microbiological conditions. Knowledge of biodeterioration of optical glass deterioration is badly needed due to marginal and scarce reference in literature to auxiliary materials used in the technology of optical devices. The main aim of our study was to investigate this phenomenon. Earlier studies showed that lubricants used as auxiliary materials in the production of optical devices can be easily assimilated by conidia of fungi.

\section{Experimental}

\section{Materials and Methods}

Biological materials. The fungus Aspergillus niger ŁOCK 0439 from the Microorganisms Pure Culture Collection Institute of Fermentation Technology \& Microbiology Technical University of Łódź were used as the biological material in our studies. They were characterized as an acid generating strain which creates citric, malic and oxalic acids when growing on a mineral background with glucose. Aspergillus strains are most often mentioned in literature as agents causing glass corrosion.

\section{Technical materials}

Optical glass. The chemical composition of the technical material (optically polished smooth glass discs, $3 \mathrm{~mm}$ thick and with $30 \mathrm{~mm}$ diameter) is shown in Table I. Light kron type glass lens (BK7 and BaK4) have small coefficients of light diffraction $n=1.45-1.6$. Heavy flint type glass lens (SF2 i F2 have coefficients of light diffraction $n=1.55-1.9$ and they contain $\mathrm{Pb}$ (ca. 50\%).

Lubricant 4 CKP. We studied a lubricant of commercial origin used to lubricate spectacle threads and hinges in optical devices exposed to rotations of the lens and eyepiece. The biodeterioration of optical glass was assessed during the growth of fungi in static and submerged conditions.

Components basal medium Mo. glucose $0-0,1 \%$, $\left(\mathrm{NH}_{4}\right)_{2} \mathrm{SO}_{4} 0,3 \%, \mathrm{KH}_{2} \mathrm{PO}_{4} 0,1 \%, \mathrm{MgSO}_{4} * 7 \mathrm{H}_{2} \mathrm{O} 0,5 \%$, agar $0-0,3 \%$, aqua dest. $\mathrm{p} \mathrm{H}=6.0$

Cultivation of $A$. niger in static conditions. Samples of optical glass were cleansed by immersing them in ethanol ( $70 \%$ conc.) and then they were placed on Petri plates with aqueous agar. The glass surface was covered with 4CKP lubricant layer and then with a small quantity of Mo medium $(0.1 \%$ glucose and $0.3 \%$ agar) to initiate the growth of microorganisms. The culture was grown in a thermostat at $30^{\circ} \mathrm{C}$ at

Table I

Chemical composition of the tested optical glass

\begin{tabular}{|c|c|c|c|}
\hline Item & Glass type & Sample mass $[\mathrm{g}]$ & Mass composition [\%] \\
\hline 1 & BK 7 & 7.8 & $\begin{array}{cc}\mathrm{SiO}_{2} & 68,9 \\
\mathrm{~B}_{2} \mathrm{O}_{3} & 10,1 \\
\mathrm{Na}_{2} \mathrm{O} & 8,8 \\
\mathrm{~K}_{2} \mathrm{O} & 8,4 \\
\mathrm{BaO} & 2,8 \\
\mathrm{As}_{2} \mathrm{O}_{3} & 1,0\end{array}$ \\
\hline 2 & $\mathrm{BaK} 4$ & 6.4 & $\begin{array}{c}\mathrm{SiO}_{2} \\
\mathrm{~B}_{2} \mathrm{O}_{3} \\
\mathrm{Na}_{2} \mathrm{O} \\
\mathrm{K}_{2} \mathrm{O} \\
\mathrm{ZnO} \\
\mathrm{BaO} \\
\mathrm{As}_{2} \mathrm{O}_{3} \\
\mathrm{PbO}\end{array}$ \\
\hline 3 & SF 2 & 7.8 & $\begin{array}{c}\mathrm{SiO}_{2} \\
\mathrm{Na}_{2} \mathrm{O} \\
\mathrm{K}_{2} \mathrm{O} \\
\mathrm{PbO} \\
\mathrm{As}_{2} \mathrm{O}_{3}\end{array}$ \\
\hline 4 & F 2 & 7.3 & $\begin{array}{cc}\mathrm{SiO}_{2} & 46,96 \\
\mathrm{~K}_{2} \mathrm{O} & 6,30 \\
\mathrm{PbO} & 46,91 \\
\mathrm{As}_{2} \mathrm{O}_{3} & 0,23\end{array}$ \\
\hline
\end{tabular}


controlled relative air humidity of abt. $80 \%$ during 3 , 6 and 12 months. To prevent drying, the samples were placed in plastic containers. After incubation time, the glass surfaces were cleansed with ethanol and surface changes were observed under of a phase-contrast microscope. Photos of the surfaces were recorded with a high resolution CCD digital camera and then processed with MicroScan graphic programs.

The destruction of the glass surface was also assessed using a helium-neon laser which was emitting a beam with the wavelength of $\lambda=0.6328 \mu \mathrm{m}$ and power of $\mathrm{P}=7 \mathrm{~mW}$. The laser beam was directed perpendiculary at the surface of the optical glass. The samples were placed on an optical stand with the possibility of precise movement. The light beam power was measured after it passed through the studied sample. The power measurements for particular glass samples were made in 5 randomly chosen points along the glass diameter. A glass disc that had not been subjected to the influence of microorganisms was the reference sample.

Mean beam power $\mathrm{I}_{\mathrm{sr}}$ was calculated on the basis of five measurements of transmittance through a parallel wall plate with a perpendicular light using the following formula:

$$
I_{s r}=\frac{\sum_{i=1}^{n} I_{i}}{n}
$$

Where: $I_{i}$ - intensity (power) of the laser beam after passing through the sample; $\mathrm{n}$ - number of measurements.

We also estimated the transmittance of the laser light $\mathrm{T}$ through the optical glass sample and this parameter was connected to the thickness of the glass plate using formula (2):

$$
T=\frac{I_{s r}}{I_{0} \times g}
$$

Where: $\mathrm{I}_{\mathrm{sr}}-$ mean power of the laser beam after passing through the sample $[\mathrm{mW}] ; \mathrm{I}_{0}$ - intensity (power) of the laser beam in air [mW]; $\mathrm{g}$ - thickness of the glass plate $[\mathrm{mm}]$

It must be underlined that in these studies $\mathrm{T}$ is the transmittance connected to unitary sample thickness.

Results of measurements of the light transmittance through samples subjected to deteriorating conditions are shown as histograms. Histograms are also shown for laser transmittance through an unaffected clean reference glass sample.

Growth of A.niger submerged conditions. Sterile optical glass samples were placed in polypropylene Erlenmeyer bulbs with a liquid medium Mo with $\mathrm{pH}=6$ with the addition of 5\% 4CKP lubricant (no glucose). Such samples were then infected with a suspension of $A$. niger spores with the density of $10^{6} / \mathrm{ml}$ and at $2 \%$ in relation to the medium volume. The culture was grown for $240 \mathrm{~h}$ at $30^{\circ} \mathrm{C}$ on a UNITRONIC OR P SELECTA shaker at $70 \mathrm{rpm}$. Optical glass samples removed from the bulbs were immersed in ethanol to deactivate the biological material and then it was delicately removed from the surface. Then the culture was pasteurized to stop the activity of the microorganisms. Post-culture liquid was analyzed with quantities of radicals freed from glass with flame atomic absorption spectrometry using a Merck ASA GBC 932 spectrometer.

Changes on the surface of optical glass were assessed on the basis of observations under a phase-contrast microscope and with the use of a laser beam.

The results reported in this paper are an arithmetic mean from three measurements with the exception of laser light transmittance measurements where a mean from five measurements was calculated. Microsoft Excel program was used to analyze the data.

\section{Results}

Biodeterioration of optical glass induced by 4CKP lubricant in a static culture of $\boldsymbol{A}$. niger. The macroscopic picture of $A$. niger growth on BaK4 glass covered with 4CKP lubricant is shown in Fig. 1A similar active growth of the spawn was noted for all glass types.

Microscopic observations of glass surface samples after 3 and 6 months of $A$. niger growth did not show any deteriorating changes of glass even if a plentiful growth was noted. Only after 12 months the glass surfaces started to show first signs of structural changes. Observations under a phase-contrast microscope allowed seeing matt areas and spot discoloring (Fig. 2). Similar changes were also observed on other glass surfaces except for BK7 glass.

Measurements of transmittance of light passing through the glass disc confirmed that the culture of

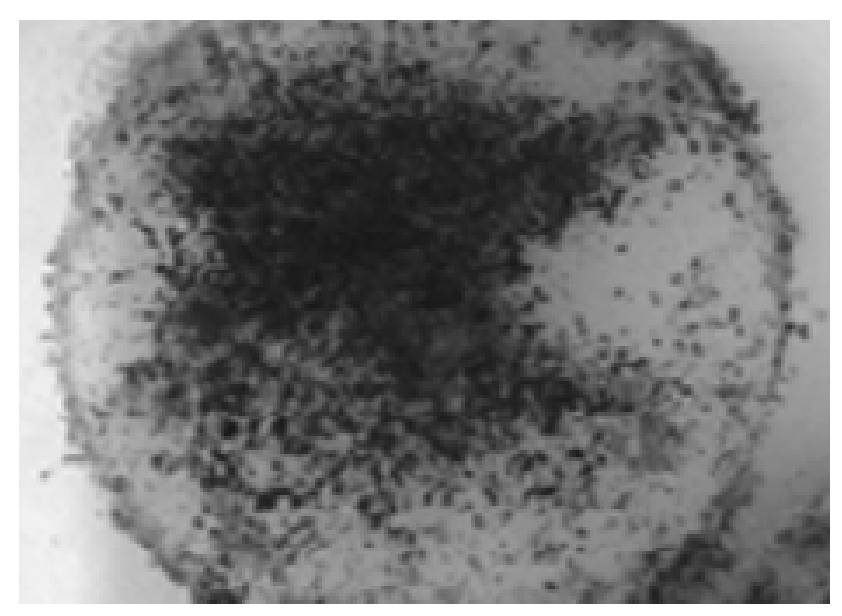

Fig. 1. Surface of glass BaK4 covered with 4CKP lubricant after 12 months of $A$. niger growth. 


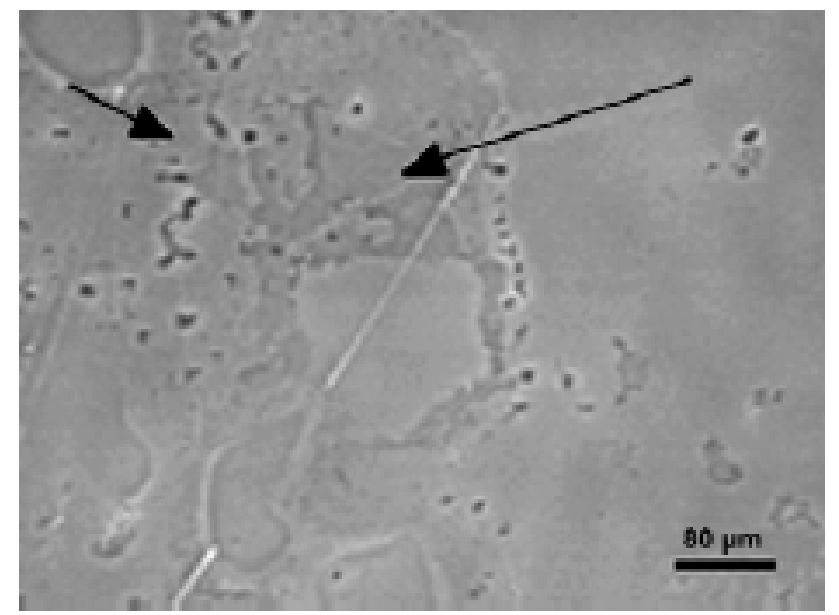

Fig. 2. Surface of BaK4 optical glass covered with $4 \mathrm{CKP}$ lubricant after 12 months of $A$. niger growth

(arrows-matt areas, discolorations).

A. niger did not show any changes after either 3 or 6 months. After 12 months though, smaller transmittance of laser light through the disc was determined for all types of investigated glass (Fig. 3). The value of transmittance of laser light through BaK4 and F2 glass samples decreased by $1.6 \%$ so the surface changes were small. The same value for SF2 glass decreased by $7.8 \%$ compared to the initial value. For BK 7 glass this transmittance decreased by a statistically insignificant $0.7 \%$ indicating that this type of glass is most resistant to deterioration caused by active growth of the $A$. niger spawn on 4CKP lubricant (Fig. 3).

Biodeterioration of optical glass in submerged conditions of $\boldsymbol{A}$. niger growth on a glass base with the addition of 4CKP lubricant. The influence of $A$. niger metabolites on the process of glass deterioration was also observed during immersed culture

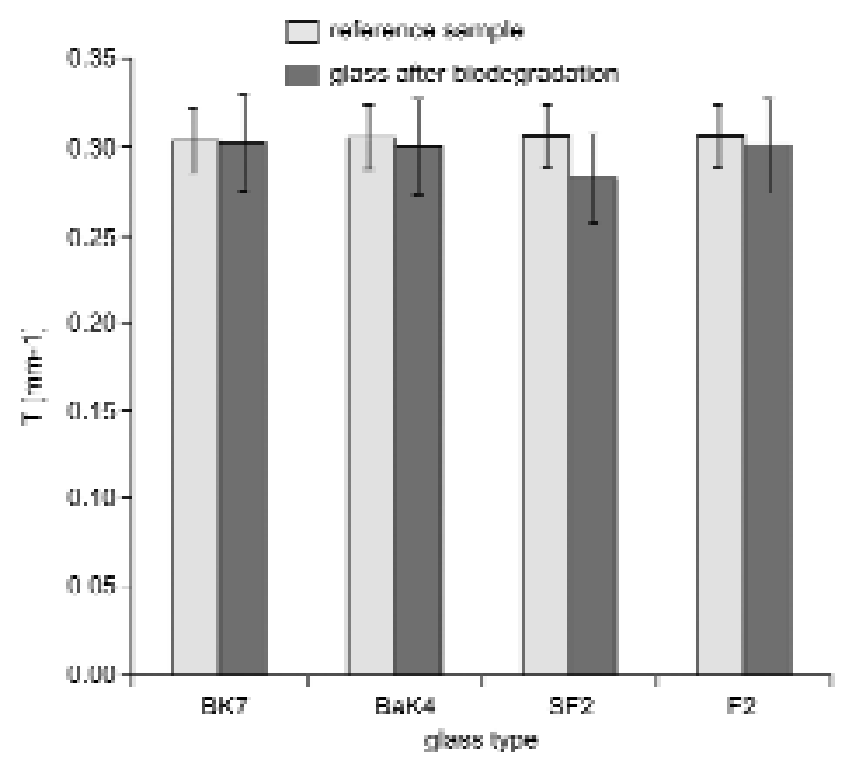

Fig. 3. Transmittance of laser light beam through optical glass after 12 months of cultivation of $A$. niger induced by 4CKP lubricant. conditions where, as in the earlier experiment, the 4CKP lubricant was the only source of carbon.

After $240 \mathrm{~h}$ of $A$. niger growth, phase-contrast microscopic observations of the glass surface did not confirm any changes in the structure of the investigated glass types. Laser light beam transmittance measurements confirmed earlier determinations that only the BK7 glass structure remained unchanged. Other glass types showed the decrease of this parameter in relation to initial values by $5.2 \%, 2.3 \%$ and $2.8 \%$ respectively for BaK4, F2 and SF2 glass samples (Fig. 4).

Atomic absorption spectrometry (AAS) chemical analysis of the post-culture liquid confirmed the destruction of glass caused by A.niger metabolites.

Small quantities of $\mathrm{Na}, \mathrm{Si}, \mathrm{K}, \mathrm{Zn}, \mathrm{Pb}$ cations were found in the medium without glass which was the reference sample (Fig. 5). The \% increase of content of particular cations in the solution was assessed in relation to the reference sample. The greatest increase of cation contents in the post-culture liquid was noted for the sample with BaK4 and SF2 glass. The Si and $\mathrm{K}$ content increased by $90 \%$ while in the solution with $\mathrm{SF} 2$ glass the $\mathrm{Pb}$ content also increased by $96 \%$. Large quantities of lead were freed from the F2 glass. Its content increased by $97 \%$ while for silica and potassium the increase was $59 \%$ and $36 \%$, respectively. In the experiment with BK7 glass the quantity of silica in the post-culture liquid increased by only $63 \%$ despite the fact that the content of $\mathrm{SiO}_{2}$ is the greatest in this type of glass. Boron was transferred to the solution in greater quantity, i.e. $99 \%$ more in relation to the reference sample. This cation can react with organic acids produced by the $A$. niger strain and form soluble salts in the solution. BK7 glass was the only investigated glass type that did not contain any lead cations

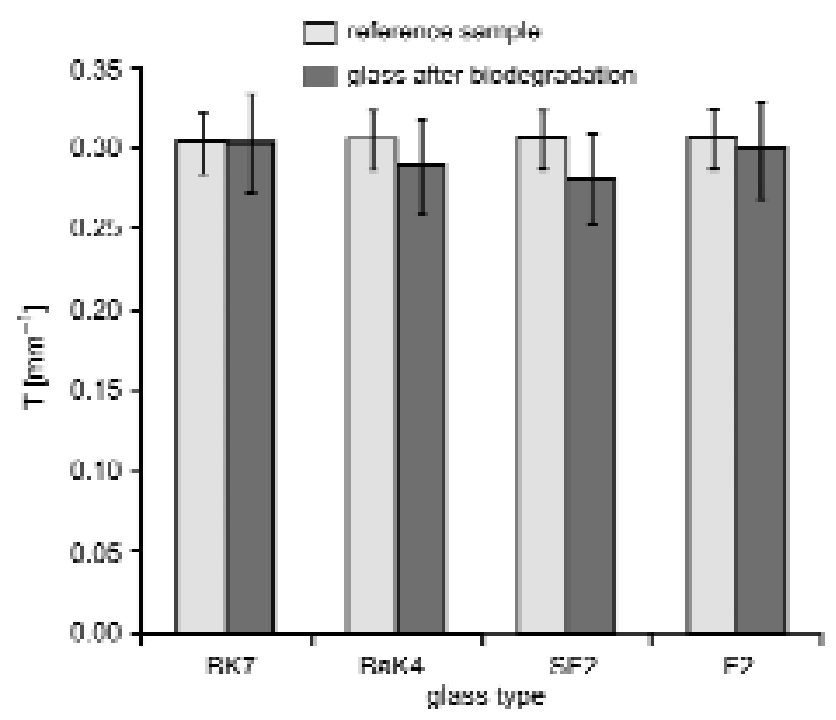

Fig. 4. Transmittance of laser light beam through glass samples deteriorated during $240 \mathrm{~h}$ of $A$. niger growth in a Mo base with the addition of 4CKP lubricant. 


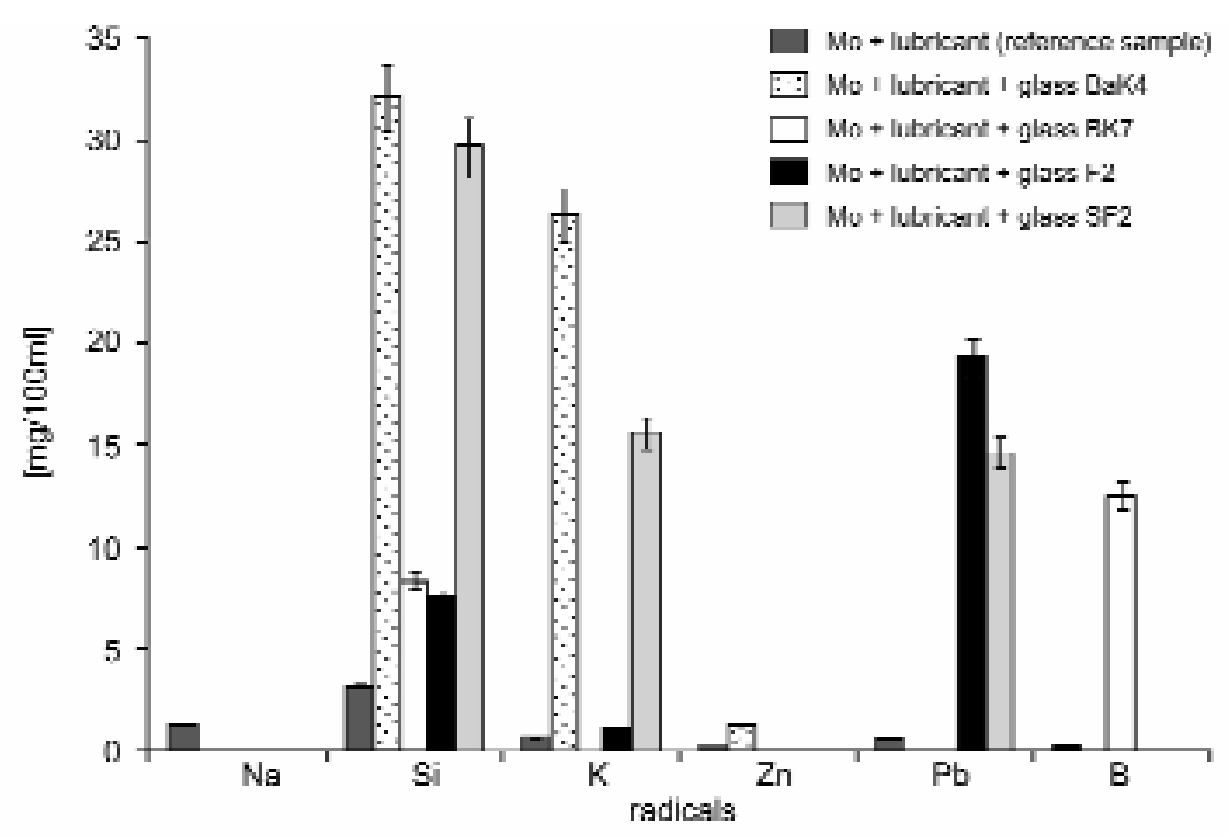

Fig. 5. Chemical radicals in the liquid after $240 \mathrm{~h}$ of submerged $A$. niger growth on $\mathrm{M}_{\mathrm{o}}$ base with the addition of 4 CKP lubricant and optical glass.

but had the greatest content of $\mathrm{SiO}_{2}$ (ca 70\%). This can explain its greater resistance to destructive influence of biological corrosion caused by A. niger. Glass types with low $\mathrm{SiO}_{2}$ content and with $\mathrm{PbO}$ (SF2, F2) have a lower resistance to the influence of acid metabolites. Thus they are more sensitive to surface destruction caused by growth of fungi.

\section{Discussion}

Biodeterioration of glass is a long and complex process. Nevertheless, it is known that in an environment of high air humidity, temperature and carbon availability, microorganisms and especially fungi can damage this seemingly durable surface. Surface dirt, putty and lubricant traces or insects can be the source of carbon that initiate the growth of microorganisms. This means that optical glass parts being parts of both civilian and military devices are exposed to the destructive action of microorganisms. Hence the knowledge of the biodeterioration of glass induced by ancillary materials used in the production of optical devices is indispensable to ensure their usefulness and durability. Earlier studies on the resistance of ancillary materials proved that among the studied materials 4CKP lubricant is most susceptible to the growth of $A$. niger. Investigations of glass surface with a thin layer of particularly susceptible ancillary material (4CKP lubricant) and grafted with a suspension of A. niger spores showed that changes of the BaK4, SF2 and F2 glass samples take place very slowly. They take the shape of matt areas and spot discolorations and can be seen under the phase-contrast microscope only after 12 months of the culture growth. No such changes were observed on the surface of BK7 glass. A more proper assessment of the surface changes was made when measuring laser light transmittance through the tested material. It was determined that small changes of the SF2 glass structure occurred already after 6 months of the A. niger growth. However the BK7 glass resistance was confirmed as high since the transmittance of light was observed only after 12 months (insignificant level of $0.7 \%$ ).

The content of elements in the post-culture liquid indicate that reactions take place between $A$. niger metabolites and glass components. Silica, lead and potassium were released from SF2 and F2 glass and silica and boron from BK7 glass. The release of boron and potassium from BaK4, SF2 and F2 glass is the result of reactions occurring between glass components and organic acids released to the base by $A$. niger. This strain has been characterized as an acid generating fungus which releases citric, oxalic and malic acids. The investigated glass types can thus be described as not resistant to the influence of the above acidic metabolites. Silica does not react with organic acids so its presence in the post-culture liquid is the result of other mechanisms. It is probable that the wash out of other cations reacting with organic acids could have been the reason for surface changes and some amount of silica could have been transferred to the solution. Richens (1997) and Drewello and Weissmann (1997) state that the reaction of organic acids with cations (components of glass) leads to the formation of soluble complex compounds and thus an 
opening and weakening of the silica structure with easier release of the silica.

Results of transmittance of laser light through investigated optical glass types showed that reactions of $A$. niger metabolites (created during the growth process on 4CKP material) decreased the transmittance of light through SF2, BaK4 and F2 glass by $2-8 \%$. They did not, however, cause any changes in the structure of BK7 glass surface which could have been recorded by the light transmittance measurements. Si and B cations found in the post-culture liquid could have been released from the rim of unpolished part of the glass disc without any changes in the transmittance of light through the polished optically smooth surface layer.

The results of these experiments justify the statement that the higher the content of $\mathrm{SiO}_{2}$ in glass, the higher its resistance to the attack of microorganisms (example-BK7 glass). On the other hand the greater the $\mathrm{PbO}$ content (SF2 and F2 glass) and the richer the composition of elements in glass which react with organic acids (BaK4 glass) the greater the susceptibility of the glass surface to microbiological corrosion.

Results obtained from the experiments are in agreement with the analyses of Drewello and Weismann (1997) of the potassium-calcium-silica glass surface (composition: $\mathrm{K}_{2} \mathrm{O} 12-25 \%$; $\mathrm{CaO}, 18-25 \% ; \mathrm{SiO}_{2}$ $47-54 \%$; $\mathrm{PbO} 0-1.5 \%$ ) attacked by fungi and of optical F2 glass (composition: $\mathrm{PbO} 24,1 ; \mathrm{SiO}_{2} 62.6 \%$; $\mathrm{K}_{2} \mathrm{O} 8.5 \%$ ). They determined that the glass surfaces with $\mathrm{K}_{2} \mathrm{O}, \mathrm{CaO}$ and $\mathrm{PbO}$ are more susceptible to the attack of filamentous fungi. The authors also stressed that the boron-silica BK7 glass and the sodium-calcium-silica glass from the year 1900 with a high $\mathrm{SiO}_{2}$ content $(72-74 \%)$ have a higher resistance to the effect of organic acids.

Similar results were obtained by Garcia-Vales et al. (2003) during studies on the biodeterioration of stained glass windows from XIII-XV centuries. They found most symptoms of microbiological corrosion in stained glass windows with glass of high $\mathrm{K}$ and $\mathrm{Ca}$ content (ca. 18\% and $20 \%$ respectively) and least in those with high $\mathrm{SiO}_{2}$ content ( $c a .60 \%$ ). References to glass production technology (Jabłkowski, 1962) indicate that the resistance of glass to acids grows with the content of $\mathrm{SiO}_{2}$ whereas lead type glass is susceptible to the influence of both inorganic and organic acids.

A new element in the state of knowledge on microbiological corrosion of glass is the fact that lubricants (an example here is the investigated 4CKP lubricant) can initiate the growth of conidia of fungi and in consequence cause glass deterioration. Results of investigations of the biodeterioration of glass do not give so far information on the threats of using ancillary materials in inducing microbiological corrosion.

Lubricants used in the production of optical devices should therefore be resistant to biodeterioration and should not contain components assimilable by microorganisms. Additionally, the resistance tests for these materials should be conducted in reference to fungi since organic acids with strong corrosive properties are their main metabolites.

\section{Acknowledgements \\ This research was supported by the Polish Ministry of Science and Higher Education (MNiSW), grant number N508 016 31/1178.}

\section{Literature}

Bartosik M., Z. Żakowska, L. Klimek and J. Szumigaj. 2007. Korozja mikrobiologiczna szkła optycznego. Ochrona przed Korozja 50, 7: 294-296.

Carmena N., L. Laiz, J.M. Gonzalez, M. Garcia-Heras, M.A. Villegas and C. Saiz-Jimenez. 2006. Biodeterioration of historic stained glasses from the Cartuja de Miraflores (Spain). International Biodeterioration \& Biodegradation 58: 155-161.

Cwalina B. 2003. Role of microorganisms in deterioration of building stones. Journal of the Polish Mineral Engineering Society 1, 9: 39-48.

Dade H.A. 1958. Moulding of lenses. C.P. News 4: 17-19.

Drewello R. and R. Weissmann. 1996. Microbially influenced corrosion of silicate glass. Biodeterioration and Biodegradation papers of 10th International Biodeterioration and Biodegradation Symposium, Hamburg, 133, 17-22.

Drewello R. and R. Weissmann. 1997. Microbially influenced corrosion of glass. Applied Microbiology and Biotechnology 47: 337-346.

Garcia-Valles M., D. Gimeno-Torrente, S. Martinem-Manent and J.L. Fernandez-Turiel. 2003. Medieval stained glass in a Mediterranean: typology, weathering and glass decay and associated biomineralization processes and products. American Mineralogist 88: 1996-2006.

Gorbushina A.A. and K.A. Palinska. 1999. Biodeteriorative process on glass: experimental proof of the role of fungi and cyanobacteria. Aerobiologia 15: 183-191.

Jabłkowski J. 1962. Glass and its properties. Technology of glass (in Polish). Arkady, Warszawa 59-61.

Janda K. 2005. Microorganisms in mechanical oils lubricants. Microbiology of materials, (eds) B. Zyska, Z. Żakowska (in Polish). Wydawnictwo Politechniki Łódzkiej, Łódź, 459-462.

Kaiser J.P., S. Trumpler and P. Raschle. 1996. In: Hertz E., Flemming H. C., Sand W. (eds.) Microbially influenced corrosion of materials. Springer, Berlin, 353-357.

Kerner-Gang W. 1968. Zur frage der Entstehung von Schimmelpilzpuren auf optischen Gläsern. Material und Organismen 4: 291-296.

Ohtsuki T. 1943. Über das Verschimmeln der gläsernen Gegenstande. Proceedings Imp. Academy of Tokyo 19: 688-693.

Richens M. (1997): Attack on Glass: Corrosion attack mechanisms. http://ceramic-materials.com/cermat/education/143.html Szumigaj J., Z. Żakowska and L. Klimek. 2008. Exopolysaccharide production by Bacillus strains colonizing packaging foils. Polish Journal of Microbiology 57, 4: 281-287.

Watkins R.D. 2003. Mould in optical instruments. J. Comm. Eye Health 16, 46: 28-29.

Weissman R. and R. Drewello R. 1996. Attack on glass. In: E. Hertz, H.C. Flemming, W. Sand (eds.) Microbially influenced corrosion of materials. Springer, Berlin, 339-352.

Zyska B. 2001. Microbiological disasters, malfunctions and hazards in industry and heavy constructions (in Polish). Wydawnictwo Politechniki Łódzkiej, Łódź. 